\title{
Response of physiological characteristics and grain yield of winter wheat varieties to long-term heat stress at anthesis
}

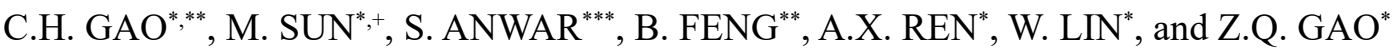 \\ College of Agriculture, Shanxi Agricultural University, No. 1, 030801 Taigu, Shanxi, China* \\ Crop Research Institute, Shandong Academy of Agricultural Sciences, No.202, 250100 Ji'nan, Shandong, China** \\ Institute of Molecular Biology and Biotechnology, The University of Lahore, Lahore, Punjab, Pakistan ${ }^{* * *}$
}

\begin{abstract}
Heat stress has become more common in recent years, limiting wheat production in Huang-Huai-Hai plain in China. To identify the effect of long-term heat stress on wheat production, two heat-resistant (JM44, JM23) and two heatsensitive (XM26, GC8901) wheat varieties were sown in heat tents and normal conditions, and heat stress (9 to $12^{\circ} \mathrm{C}$ higher than control) was imposed for seven days at post-anthesis. All varieties under heat stress exhibited early senescence and reduced grain-filling rate, while the grain-filling period of heat-tolerant varieties was longer than that of the heat-sensitive. Furthermore, long-term heat stress significantly reduced kernel mass, grain number, harvest index, chlorophyll content, maximum quantum yield of PSII photochemistry, effective quantum yield of PSII photochemistry, photosynthetic rate, and transpiration efficiency. In addition, the distribution of dry matter to vegetative organs, catalase activity, and malondialdehyde content increased. These results indicated that the lesser yield reduction of heat-resistant varieties (11-26\%) than that of heat-sensitive $(16-37 \%)$ is due to relatively higher antioxidative and photosynthetic performance and higher assimilation in the grain from vegetative organs.
\end{abstract}

Keywords: antioxidants; chlorophyll fluorescence; grain filling; heat stress duration; photosynthesis; Triticum aestivum L.

\section{Introduction}

The regional high temperature has often occurred due to global warming in recent years. The global mean temperature is predicted to increase $0.3-4.8^{\circ} \mathrm{C}$ by the end of the $21^{\text {st }}$ century (IPCC 2018), damaging crop production
(Ye et al. 2013, Tack et al. 2015). In addition, wheat, as one of the important worldwide staple cereals is susceptible to heat stress during the vegetative and grain-filling phase (Farooq et al. 2011, Balla et al. 2019), and heat stress at these stages could limit wheat growth and grain yield (Wang et al. 2012, Bergkamp et al. 2018).

\section{Highlights}

- Heat stress reduced grain yield of four wheat varieties due to a decrease in kernel mass and grain number

- Heat stress reduced photosynthetic performance and improved antioxidant capacity

- Heat-resistant varieties performed better than sensitive varieties under heat stress
Received 13 July 2021

Accepted 19 November 2021

Published online 6 December 2021

${ }^{+}$Corresponding author

e-mail: sm_sunmin@126.com

\footnotetext{
Abbreviations: CAT - catalase; CK - control treatment; DM - dry mass; $E$ - transpiration rate; $\mathrm{F}_{\mathrm{v}} / \mathrm{F}_{\mathrm{m}}-$ maximum quantum yield of PSII photochemistry; GC8901 - Gaocheng8901; GN - grain number; GY - grain yield; H - heat stress treatment; HI - harvest index; JM23 - Jimai23; JM44 - Jimai44; MDA - malondialdehyde content; $P_{\mathrm{N}}$ - net photosynthetic rate; S - season; SOD - superoxide dismutase; SPAD - chlorophyll content; TCA - trichloroacetic acid; TE - transpiration efficiency; TKM - thousand kernel mass; $\mathrm{V}$ - variety; XM26 - Xinmai26; $\Phi_{\mathrm{PSII}}$ - effective quantum yield of PSII photochemistry.

Acknowledgments: This research was funded by 'Modern Agriculture Industry Technology System Construction' (CARS-03-01-24) and '1331, Engineering Key Innovation Cultivation Team - Organic Dry Cultivation and Cultivation Physiology Innovation Team' (No. SXYBKY201733).
}

Conflict of interest: The authors declare that they have no conflict of interest. 
The effects of high temperature on wheat growth and yield vary with the duration of heat stress and genotypes by differentially influencing photosynthetic performance, grain-filling duration, dry matter accumulation, and allocation to grain (Tahir and Nakata 2005, Fahad et al. 2016). It has been identified that heat stress at the reproductive stage had a more significant impact on grain yield than that at the vegetative stage (Farooq et al. 2011, Balla et al. 2019). It has been reported that the wheat yield reduction under heat stress varied between varieties ranging from 2 to $27 \%$ in the field conditions, and the proportion of green crop area varied from 7 to $98 \%$ (Schittenhelm et al. 2020).

Heat stress at post-flowering accelerated the senescence of the leaves and grain-filling process, resulting in a shorter grain-filling period and early ripening (Dias and Lidon 2009, Yin et al. 2009, Schittenhelm et al. 2020). It has been reported that every $1^{\circ} \mathrm{C}$ increase in temperature above the optimum growth temperature had shortened the grain-filling period by $2.8 \mathrm{~d}$ (Streck 2005). The grainfilling rate increases with increasing the temperature when the temperature does not exceed $30^{\circ} \mathrm{C}$ (Wardlaw and Moncur 1995, Yin et al. 2009), which could be expected to compensate for the shorter grain-filling duration. Although when the temperature exceeds $30^{\circ} \mathrm{C}$, the grain-filling rate decreases (Viswanathan and Khanna-Chopra 2001, Dias and Lidon 2009).

Photosynthesis is one of the most sensitive physiological processes to heat stress (Ristic et al. 2007, Wahid et al. 2007, Wang et al. 2011). Numerous studies have reported that the PSII activity of crops was inhibited under heat stress which led to a reduction of chlorophyll fluorescence parameters and photosynthetic rate (Dash and Mohanty 2001, Camejo et al. 2005). The heat stress at the flowering and grain-filling period of wheat damages the structure and function of chloroplasts in wheat leaves and hinders chlorophyll (Chl) biosynthesis, reducing $\mathrm{Chl}$ content and photosynthetic rate and accelerating leaf senescence (Feng et al. 2014, Liu et al. 2017). Dry matter accumulation and partitioning to grains are important factors sensitive to heat stress that affect wheat yield (Álvaro et al. 2008, Sanghera and Thind 2014).

Previous studies have shown that most of the northern wheat-producing areas of China are at high-temperature risk (Tao et al. 2012, Tian et al. 2012, Wang et al. 2012). It has been estimated that every $1^{\circ} \mathrm{C}$ increase in temperature above the optimum growth temperature would lead to 3-10\% grain yield losses (Tian et al. 2012, Ye et al. 2013). Shandong province is the second largest wheat-producing province in China, with a planting area of 3.7 million hectares and a production of about 20 million tons (Cao et al. 2015). During the wheat grain-filling period, high temperature and hot and dry wind occurred for short to moderate periods $(\leq 5 \mathrm{~d})$ and led to a reduction of wheat grain yield (Feng et al. 2014, Cao et al. 2015). But the duration of heat stress shows an increasing trend and occurs for relatively longer periods (5-10 d). However, previous studies mainly focused on the effects of shortterm $(30 \mathrm{~min})$ and moderate-term $(\leq 5 \mathrm{~d})$ heat stress on wheat production (Feng et al. 2014, Talukder et al.
2014, Shirdelmoghanloo et al. 2016, Rezaei et al. 2018). Therefore, the effect of long-term heat stress should be studied to provide new insights for wheat production under long-term heat stress. Hence, the objectives of our studies were to determine the genetic variability and response of photosynthetic performance, chlorophyll fluorescence, antioxidant enzyme activity, grain-filling rate, and grain yield to prolonged post-flowering heat stress in field conditions to investigate the most suitable winter wheat variety for the long-lasting warm conditions in Shandong province.

\section{Materials and methods}

Experimental setup and treatments: Field experiments were carried out at the experimental station of Shandong Academy of Agricultural Sciences in Jinan city in the 2017-2018 and 2018-2019 seasons. Four winter wheat varieties, Jimai44 (JM44), Jimai23 (JM23), Gaocheng8901 (GC8901), and Ximai26 (XM26), were used for this study. The four varieties had a similar phenological period and are the main cultivars in Huang-Huai-Hai plain wheat production area in China. Two-factor (varieties and heat stress) randomized complete block design was used in the experiment.

Seeds were sown at a density of 180 seeds $\mathrm{m}^{-2}$ on 15 October 2017 and 20 October 2018. Each plot was $8 \mathrm{~m}$ in length and contained six rows of $1.5 \mathrm{~m}$ in width. The soil was brown loam and contained an average of $16.4 \mathrm{~g}$ (organic content) $\mathrm{kg}^{-1}$ in two seasons. Fertilizer with the rate of $120 \mathrm{~kg}(\mathrm{~N}) \mathrm{ha}^{-1}, 112.5 \mathrm{~kg}\left(\mathrm{P}_{2} \mathrm{O}_{5}\right) \mathrm{ha}^{-1}$, and $112.5 \mathrm{~kg}\left(\mathrm{~K}_{2} \mathrm{O}\right) \mathrm{ha}^{-1}$ was applied as a basal fertilizer before planting, with another $120 \mathrm{~kg}(\mathrm{~N}) \mathrm{ha}^{-1}$ as a top dressing at the elongation stage of wheat in the spring.

The heat stress was imposed by the heat tents placed on the established plots $10 \mathrm{~d}$ after flowering for a total of $7 \mathrm{~d}$ in each season (Fig. 1S, supplement). The heat tents ( $8 \mathrm{~m}$ length, $2.8 \mathrm{~m}$ width $\times 2 \mathrm{~m}$ in height) were constructed of steel pipe framework and covered with transparent polyethylene film $(0.7 \mathrm{~mm}$ thick $)$. The polyethylene film covering the steel frame transmitted $\geq 93 \%$ of solar radiation, and therefore the internal temperature was not affected by the solar radiation. Temperature for heat stress was maintained each day from 8:00 to 18:00 h, and then the heat stress was removed by rolling up the polyethylene film. The temperature was recorded at 30 -min intervals for the duration of the experiment from inside and outside the heat tents, using AZ8808 temperature data logger (AZ Instrument Crop, Inc., China). The sensors of the temperature data logger were mounted on a pole with appropriate shields to protect from direct sunlight and placed $10 \mathrm{~cm}$ above the canopy level both inside and outside the heat tents. During the heat stress period of the two seasons (7-13 May in 2017-2018 and 10-16 May in 2018-2019), there was no rainfall so that the soil moisture difference could be excluded between heat stress and control spots. Fungicide and insecticides were used to prevent stripe rust and aphid damage. Other cultural practices used in the present study followed high-yielding cultivation. From heat stress, the average day temperature 
from 8:00 to $18: 00 \mathrm{~h}$ inside the tent was $9-12^{\circ} \mathrm{C}$ higher than the outside control temperature in the 2017-2018 and 2018-2019 seasons, while the night temperature was similar (Fig. 2S, supplement).

Chl index and Chl fluorescence parameters: $\mathrm{Chl}$ index of flag leaves from ten marked plants having the same flowering time was measured using a hand-held Soil and Plant Analyzer Development (SPAD) chlorophyll meter (Model 502, Konica Minolta Sensing, Osaka, Japan). The SPAD values of four varieties were taken weekly starting from $7 \mathrm{~d}$ after anthesis until physiological maturity in the 2017-2018 and 2018-2019 seasons.

Chl fluorescence of the same leaves of marked plants was measured using a portable Chl fluorescence spectrometer (FMS2 chlorophyll fluorescence system, Hansatech, UK). The effective quantum yield of PSII photochemistry $\left(\Phi_{\text {PSII }}\right)$ and maximum quantum yield of PSII photochemistry $\left(\mathrm{F}_{\mathrm{v}} / \mathrm{F}_{\mathrm{m}}\right)$ of four varieties were measured after $5 \mathrm{~d}$ of heat stress imposition in 2017-2018 and 1,3, 7, and $15 \mathrm{~d}$ after heat stress imposition in 2018-2019.

Net photosynthetic rate and transpiration rate: The net photosynthetic rate $\left(P_{\mathrm{N}}\right)$ and transpiration rate $(E)$ of four varieties of the flag leaf were measured between 9:00-11:00 h on 10 May (5 d after heat stress) on a clear day in the 2017-2018 season and of JM44 and XM26 were measured on 11 May ( $1 \mathrm{~d}$ after heat stress) and then 3,7 , and $15 \mathrm{~d}$ after heat stress in the 2018-2019 season using a $L i$-Cor 6400 portable photosynthesis system (Li-Cor Inc., Lincoln, NE, USA). Measurements were taken on ten plants that were tagged on the day of anthesis in both seasons. Parameters of the measuring system were set as follows: PPFD was $1,200 \mu \mathrm{mol} \mathrm{m}^{-2} \mathrm{~s}^{-1}$; ambient $\mathrm{CO}_{2}$ was according to the atmospheric environment, and the flow speed was $500 \mu \mathrm{mol} \mathrm{s}^{-1}$ (Urban et al. 2018).

Transpiration efficiency (TE) was calculated as: $\mathrm{TE}=$ photosynthetic rate/transpiration rate.

Assays of antioxidant enzyme activities and lipid peroxidation: The flag leaves of all four varieties were collected after 1, 3, 7, and $15 \mathrm{~d}$ of heat stress in 20182019 and frozen in liquid nitrogen. Then $0.4 \mathrm{~g}$ of fresh leaves were weighed and ground into a fine powder and homogenized in $50 \mathrm{mM}$ sodium phosphate buffer $(\mathrm{pH}$ 7.0). The homogenate was centrifuged at 10,000 $\times g$ for $20 \mathrm{~min}$ at $4^{\circ} \mathrm{C}$, and the supernatant/extract was isolated and stored in aliquots at $-20^{\circ} \mathrm{C}$ for enzyme determinations. The activity of superoxide dismutase (SOD, EC 1.15.1.1) was determined by monitoring the decrease at $560 \mathrm{~nm}$ in absorbance of nitroblue tetrazolium dye (Dhindsa et al. 1981) using UV-visible spectrophotometer (UV-2600, Shimadzu, Japan). One unit of SOD activity was defined as the amount of enzyme causing a $50 \%$ inhibition in the absence of an enzyme under these conditions. Catalase (CAT, EC 1.11.1.6) activity was determined by monitoring the decrease in absorbance at $240 \mathrm{~nm}$ following the addition of the plant extract to $50 \mathrm{mM}$ phosphate buffer (pH 7.5) containing $20 \mathrm{mM} \mathrm{H}_{2} \mathrm{O}_{2}$ (Dhindsa et al. 1981). One enzyme unit of CAT activity was defined as the amount of enzyme consuming $1 \mathrm{nmol}\left(\mathrm{H}_{2} \mathrm{O}_{2}\right)$ per min.

Lipid peroxidation (MDA) was measured according to Dhindsa et al. (1981) method with some modifications. Fresh flag leaves $(0.5 \mathrm{~g})$ frozen in liquid nitrogen were ground into a fine powder and then homogenized in $2 \mathrm{ml}$ of $5 \%$ trichloroacetic acid (TCA). The homogenates were centrifuged at $10,000 \times g$ for $15 \mathrm{~min}$ at $4^{\circ} \mathrm{C}$. The reaction mixture contained $2 \mathrm{ml}$ of supernatant, $1 \mathrm{ml}$ of $20 \%(\mathrm{v} / \mathrm{v})$ TCA, and $0.5 \%(\mathrm{w} / \mathrm{v})$ thiobarbituric acid. The reaction mixture was incubated in a water bath at $100^{\circ} \mathrm{C}$ for $30 \mathrm{~min}$ and then quickly cooled in running water. The solution was centrifuged at $10,000 \times g$ for $10 \mathrm{~min}$, and the absorbance of the supernatants was measured at 450,532 , and $600 \mathrm{~nm}$ (UV-2600, Shimadzu, Japan). MDA content was calculated using the following formula: MDA $\left[\mathrm{nmol} \mathrm{g}^{-1}(\mathrm{FM})\right]=3 \times$ $\left[6.45 \times\left(\mathrm{A}_{532}-\mathrm{A}_{600}\right)-0.56 \times \mathrm{A}_{450}\right]$.

Dry matter accumulation and partitioning at maturity: Three groups were harvested from the 30 marked plants at physiological maturity in each treatment and divided into the ear, stem + sheath, and leaf, dried in an oven at $75^{\circ} \mathrm{C}$ and weighed. Grains were threshed manually from ears and weighed to calculate grain mass. Dry matter partitioning among different winter wheat organs at maturity was calculated.

Grain filling characteristics: Thirty ears of marked stems at the same anthesis stage were taken weekly after anthesis until maturity. Ears were dried in an oven at $75^{\circ} \mathrm{C}$ until the constant mass and then grains were threshed manually from ears and weighed to calculate the grain-filling rate. Cubic polynomial equation, $y=c+b_{1} t+b_{2} t^{2}+b_{3} t^{3}$ was used to simulate grain increasing dynamic characteristics; $\mathrm{b}_{1}, \mathrm{~b}_{2}$, and $\mathrm{b}_{3}$ were constants and were determined according to different varieties, $y$ and $t$ were grain mass and days after anthesis, respectively. Grain-filling rate equation $y^{\prime}=b_{1}+2 b_{2} t+3 b_{3} t^{2}$ was a derivation of a cubic polynomial equation, maximum grain-filling rate was calculated from the formula: $y^{\prime}=b_{1}-b_{2}{ }^{2} / 3 b_{3}$, at the time of $t=-b_{2} / 3 b_{3}$, and the duration of maximum grain filling was calculated as the following formula: $t^{\prime}=-2\left(b_{2}^{2}-3 b_{3} b_{1}\right)^{1 / 2} / 3 b_{3}(\mathrm{Li}$ et al. 2003).

Grain yield and yield reduction rate: At maturity, ears of wheat plants were hand-harvested from the area of $1.5 \mathrm{~m}^{2}$ and were air-dried, threshed, and grain dry mass was recorded. The heat resistance index for grain yield was calculated using the following formula: heat resistant index $=$ (grain yield of control - grain yield under heat stress)/grain yield of control $\times 100 \%$.

Statistical analyses: Bartlett test of variance for all the measured parameters in two seasons was firstly performed using SPSS software (version 18). The result of the Bartlett test indicated that it meets the homogeneity of variance (Table 1S, supplement). Analysis of variance (ANOVA) for all the measured parameters was then performed. Differences between heat, genotypes, seasons, and interaction between them were compared using Tukey's least significant difference (LSD) at the 5\% probability level. 


\section{Results}

Grain yield and yield reduction rate: In both field experiments (2017-2018 and 2018-2019), thousand kernel mass, grain numbers, grain yield, and harvest index (HI) were significantly affected by heat stress, and also affected by the interaction of season $\times$ variety and season $\times$ heat stress (Table 1). Heat stress reduced the thousand kernel mass compared to control. The reduction in thousand kernel mass, grain number per spike, and grain yield of heat-sensitive varieties were higher than that of the resistant varieties. The average of both seasons showed that a thousand kernel mass was reduced by $21,19,13$, and $12 \%$ in GC8901, XM26, JM44, and JM23, respectively, by heat stress compared to control. Similarly, GC8901 showed the highest reduction $(9.1 \%)$ in grain number per spike, followed by XM26 (8.6\%), JM44 (7\%), and JM23 (6.7\%). The grain yield of all wheat varieties was significantly reduced by heat stress in both seasons. Furthermore, heat stress caused $28.3,26.2,17.6$, and $18.8 \%$ reduction in grain yield of GC8901, XM26, JM44, and JM23, respectively, compared with control. The HI was significantly reduced by heat stress by $29 \%$ in GC8901, 29\% in XM26, $17.7 \%$ in JM23, and 9.1\% in JM44 in 2017-2018, while was not affected in 2018-2019.

Crop phenology: Days to physiological maturity were significantly affected by heat stress (Fig. 3S, supplement). Heat stress induced the early maturity while it decreased the grain-filling period of all varieties in both seasons. Among the four varieties, grain-filling duration was reduced by 2, 2, 4-5, and $4 \mathrm{~d}$ in JM23, JM44, GC8901, and XM26, respectively.

Antioxidant enzyme activities and lipid peroxidation: In the 2018-2019 experiments, SOD activity in flag leaves of four varieties showed a decreasing trend after heat stress (Fig. 1A). The SOD activities of JM44 and JM23 were both increased by heat stress as compared to control, especially at 1 and $3 \mathrm{~d}$ after heat stress. SOD activities of XM26 and GC8901 increased at 1 and $3 \mathrm{~d}$ after heat stress imposition, while decreased at 7 and $15 \mathrm{~d}$ after heat stress compared with control.

Catalase (CAT) activities of four varieties significantly increased by heat stress (Fig. 1B). The CAT activity first increased and then showed a decreasing trend with $7 \mathrm{~d}$ after heat stress imposition. CAT activities differed between varieties, and the increase in CAT activity was higher in JM44 and JM23 than that in XM26 and GC8901 all days after heat stress imposition.

MDA contents of all varieties increased with the heat stress and showed an increasing trend with time after heat stress, reaching a maximum at $15 \mathrm{~d}$ after heat stress imposition (Fig. 1C). Among varieties, the increase of MDA was higher in heat-sensitive (XM26 and GC8901) than that of heat-resistant (JM44 and JM23) varieties under heat stress.

Net photosynthetic rate and transpiration rate of flag leaves: $P_{\mathrm{N}}$ of flag leaves of all varieties decreased by heat stress compared with control in 2017-2018 (Fig. 2B). The decrease of $P_{\mathrm{N}}$ in JM44 (27\%) and JM23 (24\%) was lower than that in XM26 (36\%), and GC8901 (39\%) (Fig. $2 B)$. Then $P_{\mathrm{N}}$ was further checked in JM44 and XM26 after 1, 3, 7, and $15 \mathrm{~d}$ of heat stress in 2018-2019 (Fig. $2 A, C$ ). The $P_{\mathrm{N}}$ of heat-stressed JM44 and XM26 were significantly lower at $1,3,7$, and $15 \mathrm{~d}$ after heat stress imposition compared with control, and more reduction was observed in XM26 (Fig. 2A,C).

Heat stress significantly increased the transpiration rate (E) (Fig. $3 A$ ) while reducing the transpiration efficiency (TE) (Fig. $3 B$ ) of four varieties compared with control in 2017-2018. The increase in $E$ in JM23 (99\%) and JM44 $(112 \%)$ was lower than that in GC8901 (139\%) and XM26 (148\%) under heat stress (Fig. 3A), whereas JM23 and JM44 had higher transpiration efficiencies than that of XM26 and GC8901 under heat treatment (Fig. 3B). The $E$ of XM26 and JM44 increased after 1, 3, and $7 \mathrm{~d}$ of heat stress imposition and then remained unaffected after $15 \mathrm{~d}$ of heat imposition in 2018-2019 (Fig. 3C). The increase in $E$ was 62,63 , and $71 \%$ in XM26, and 73, 77, and $126 \%$ in JM44 after 1,3 , and $7 \mathrm{~d}$ of heat, respectively. Transpiration efficiencies decreased by $64,52,60$, and $39 \%$ in XM26, and 61, 54, 70, and 31\% in JM44 after 1, 3, 7 , and $15 \mathrm{~d}$ of heat stress imposition compared with their respective control (Fig. $3 D$ ).

Chl content and Chl fluorescence parameters: Chl contents (SPAD values) of all four varieties were significantly affected by season, variety, heat, and interaction between them (Table $2 \mathrm{~S}$, supplement). It showed decreasing trends by increasing time after heat stress in both seasons (Fig. 4). SPAD values of four varieties significantly decreased by heat stress at $14(3 \mathrm{~d}$ after heat stress imposition), 21, 28, and $35 \mathrm{~d}$ after anthesis (Fig. 4). GC8901 had the highest reduction in SPAD, followed by XM26, JM44, and JM23.

The heat stress significantly decreased the effective quantum yield of PSII photochemistry $\left(\Phi_{\text {PSII }}\right)$ of flag leaves in four varieties, while it had no significant effect on the maximum quantum yield of PSII photochemistry $\left(\mathrm{F}_{\mathrm{v}} / \mathrm{F}_{\mathrm{m}}\right)$ in JM23 and JM44 as compared with control in 2017-2018 (Fig. $5 A, B$ ). The $\mathrm{F}_{\mathrm{v}} / \mathrm{F}_{\mathrm{m}}$ of XM26 and JM44 both decreased at $1,3,7$, and $15 \mathrm{~d}$ after heat stress in 2018-2019 (Fig. 5C). The decrease rate of $F_{v} / F_{m}$ under heat stress was higher in XM26 than that in JM44 in all stages after heat stress (Fig. $5 C$ ). The $\Phi_{\text {PSII }}$ of XM26 significantly decreased after $1,3,7$, and $15 \mathrm{~d}$ of heat stress imposition, whereas $\Phi_{\mathrm{PSII}}$ of JM44 showed only a significant decrease after 1 and $15 \mathrm{~d}$ of heat stress imposition (Fig. 5D), and the decrease rate of JM44 was lower than that in XM26 at $15 \mathrm{~d}$ after heat stress.

Grain-filling rate: The maximum grain-filling rate of all varieties decreased by heat stress compared with control, but a higher reduction was observed in the 2018-2019 season than in the 2017-2018 season (Table 2). The heat-resistant varieties, JM44 and JM23, showed higher maximum grain-filling rates than the heat-sensitive varieties, XM26 and GC8901, averaging two seasons. 


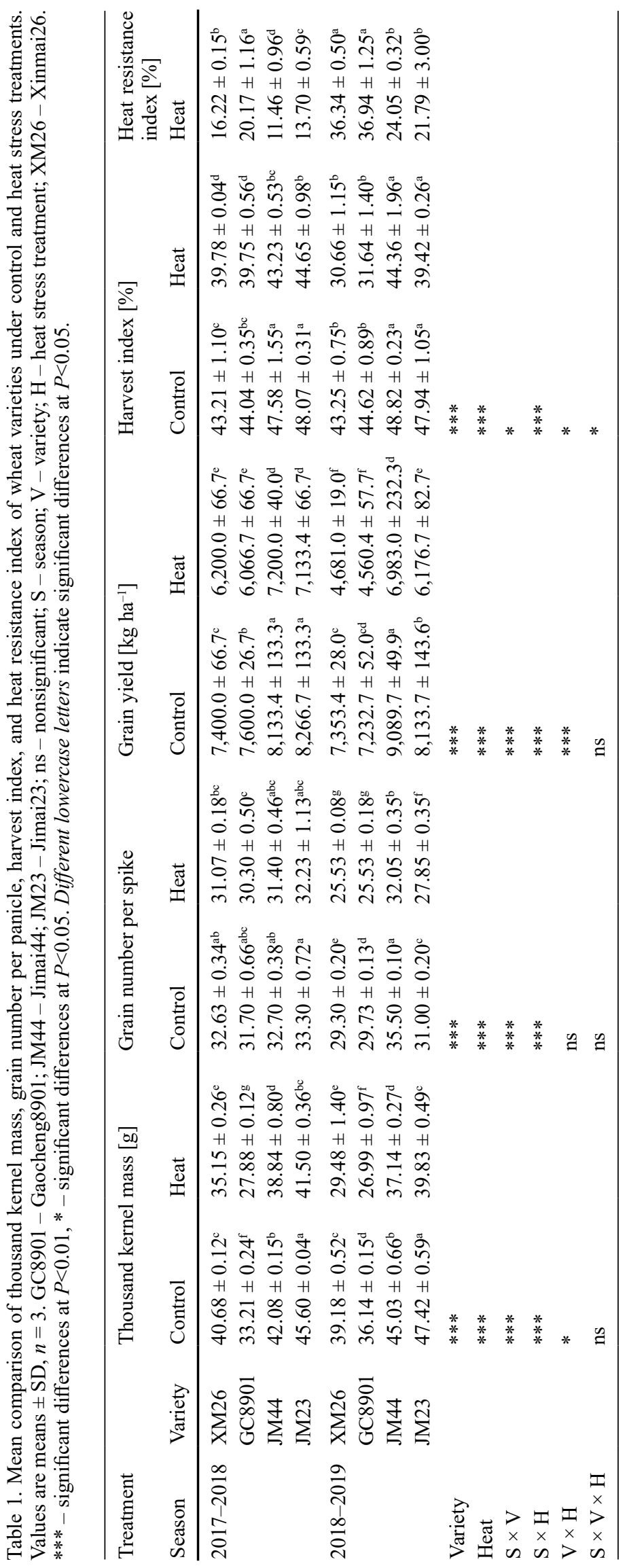




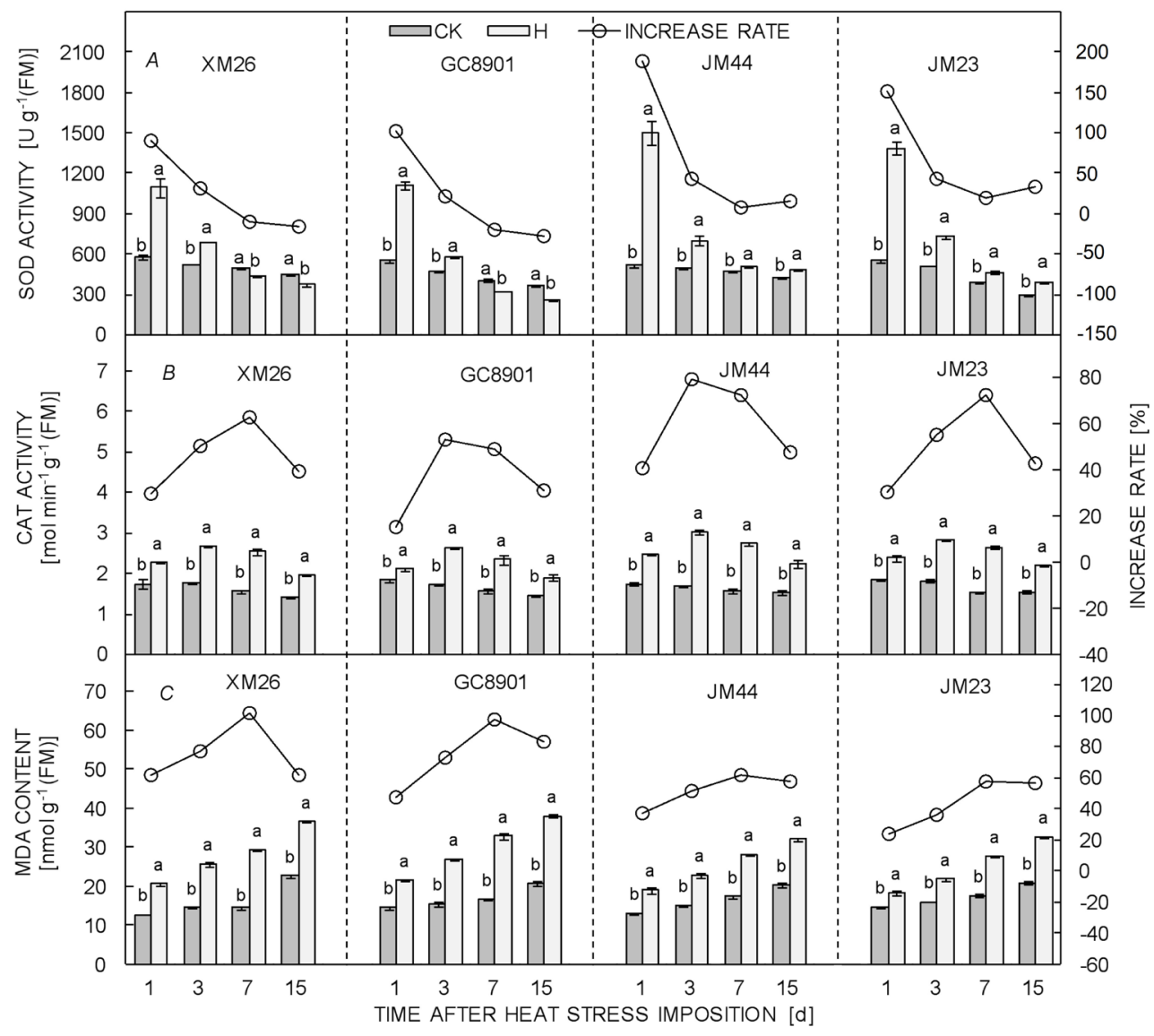

Fig. 1. Changes in superoxide dismutase (SOD) $(A)$ and catalase (CAT) $(B)$ activities and malondialdehyde (MDA) content $(C)$ of flag leaves in different wheat varieties in 2018-2019 field experiment. CK - control treatment; $\mathrm{H}$ - heat stress treatment. Values are means $\pm \mathrm{SD}, n=3$. Different lowercase letters indicate significant differences at $P<0.05$.

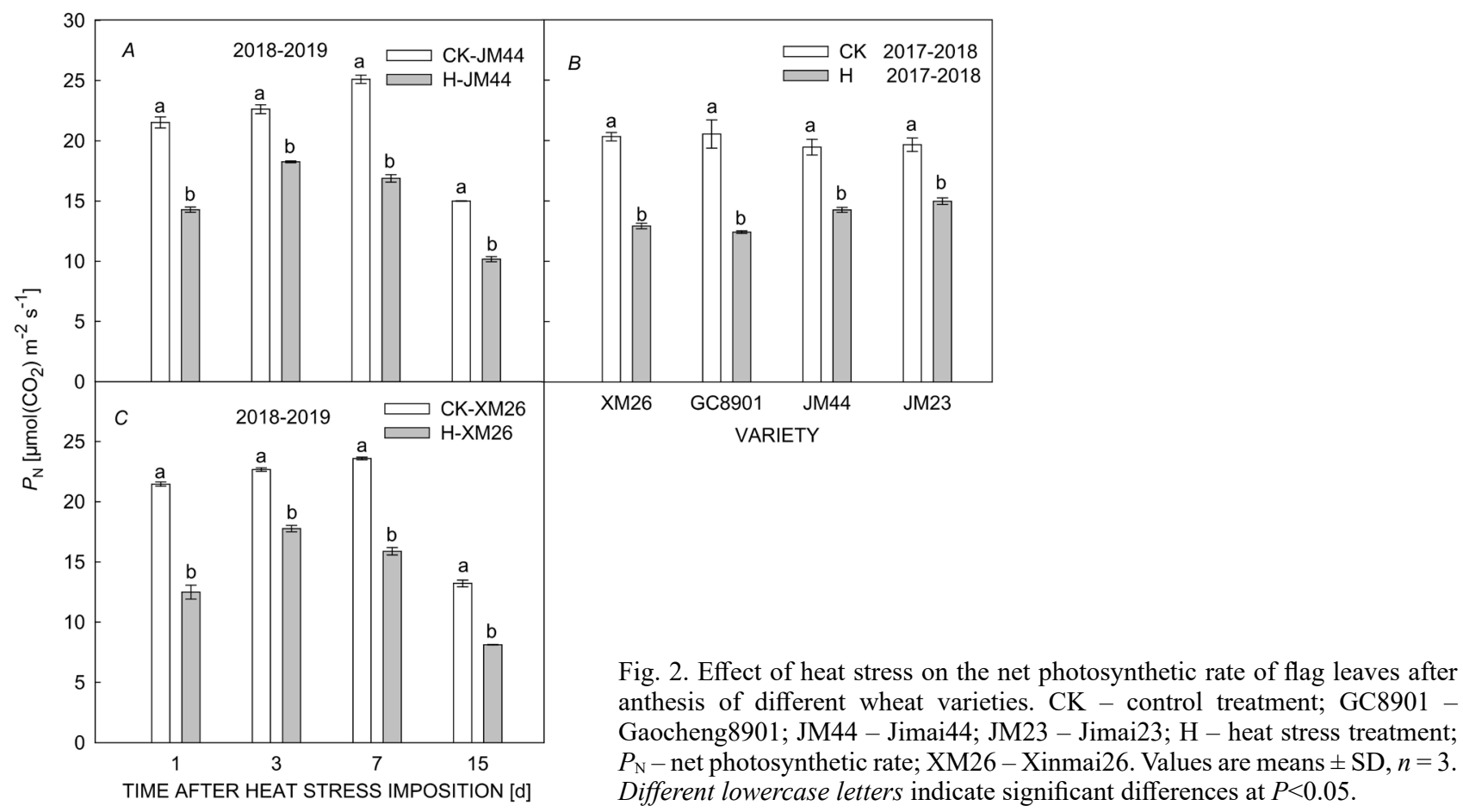




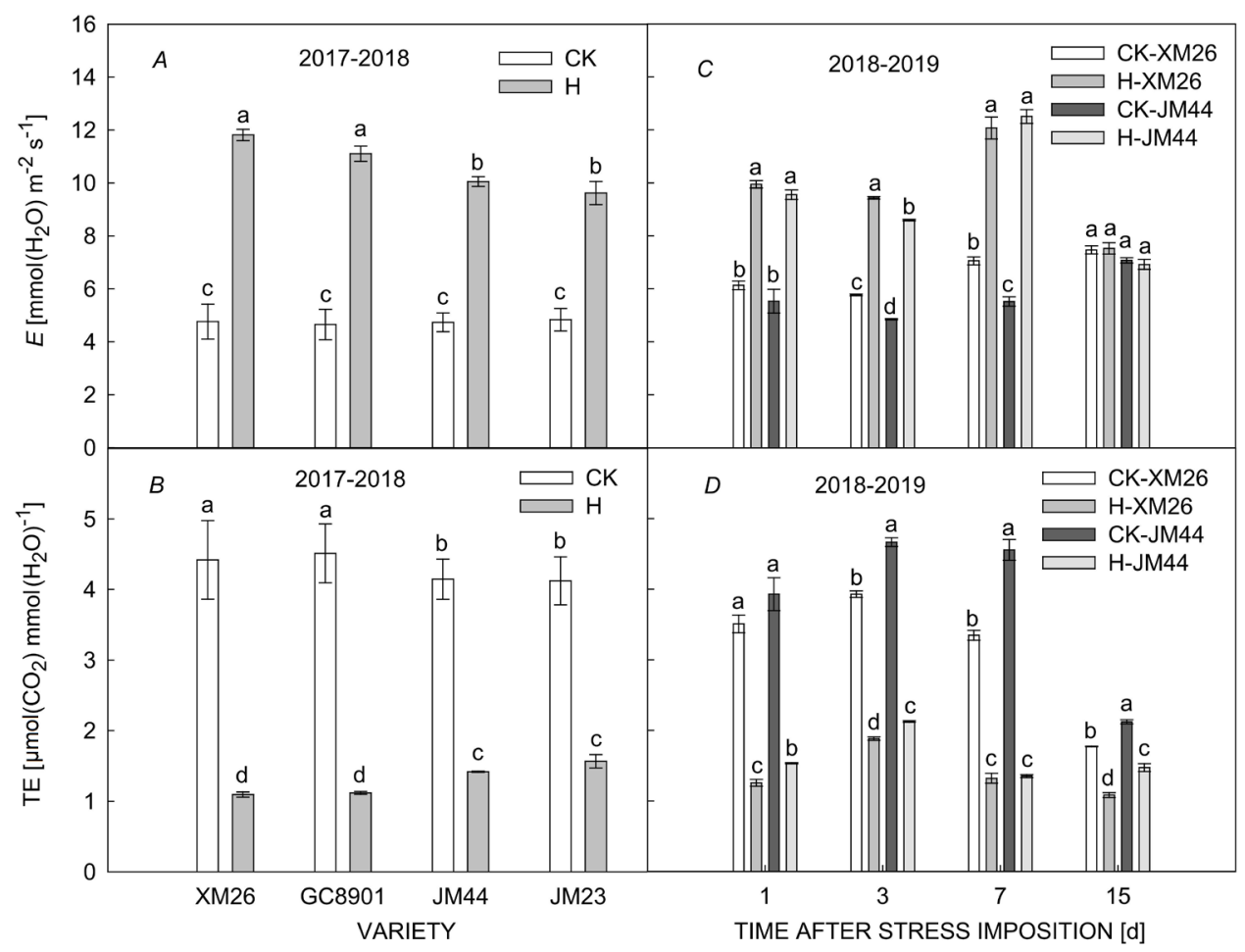

Fig. 3. Effect of heat stress on transpiration rate $(E)(A, C)$ and transpiration efficiency (TE) $(B, D)$ of flag leaves in different wheat varieties. CK - control treatment; GC8901 - Gaocheng8901; H - heat stress treatment; JM44 - Jimai44; JM23 - Jimai23; XM26 Xinmai26. Values are means $\pm \mathrm{SD}, n=3$. Different lowercase letters indicate significant differences at $P<0.05$.

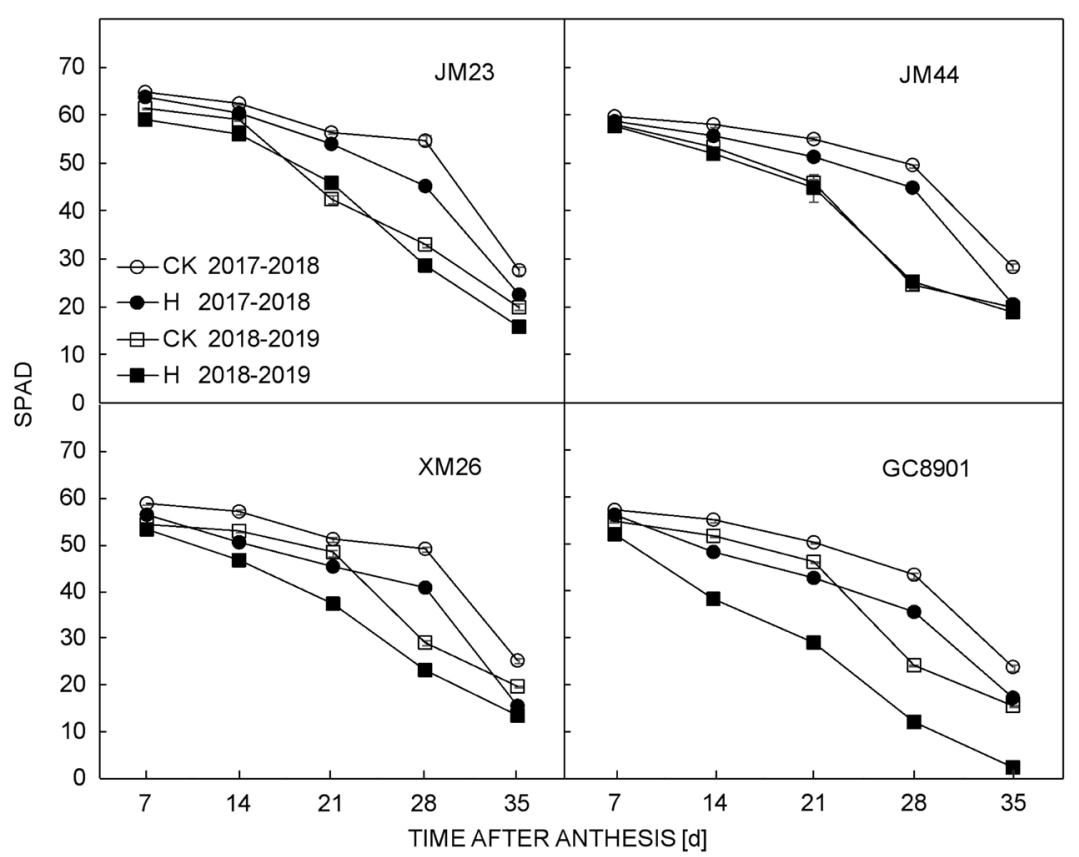

Fig. 4. Effect of heat stress on chlorophyll content of flag leaves in two seasons. CK control treatment; GC8901 - Gaocheng8901; $\mathrm{H}$ - heat stress treatment; JM44 - Jimai44; JM23 - Jimai23; SPAD - chlorophyll content; $\mathrm{XM} 26$ - Xinmai26. Values are means $\pm \mathrm{SD}$, $n=3$. Different lowercase letters indicate significant differences at $P<0.05$.
The heat treatment decreased the maximum grain-filling rate but brought forward the time of the maximum grainfilling rate, especially in heat-resistant varieties (JM44 and JM23) (Table 2). The duration of the maximum grain-filling rate of four varieties increased by heat stress except for GC8901 in 2018-2019.
Dry matter and partitioning at maturity: The plant mass and dry matter partitioning in different plant organs differed with heat treatment, seasons, and varieties (Table 3S, supplement). Under heat stress, the reduction in plant mass in XM26, GC8901, JM23, and JM44 was 11.6, $12.2,9.0$, and $7.1 \%$, respectively, as compared to control 
(Fig. 6). The grain mass decreased by 33.6, 34.6, 26.9, and $25.1 \%$ in XM26, GC8901, JM23, and JM44, respectively, averaging two seasons. Inversely, the dry masses of stem + sheath and spike axis + glume increased by heat stress. The leaf mass of JM23 was not affected by heat. The heat stress significantly increased the leaf mass of

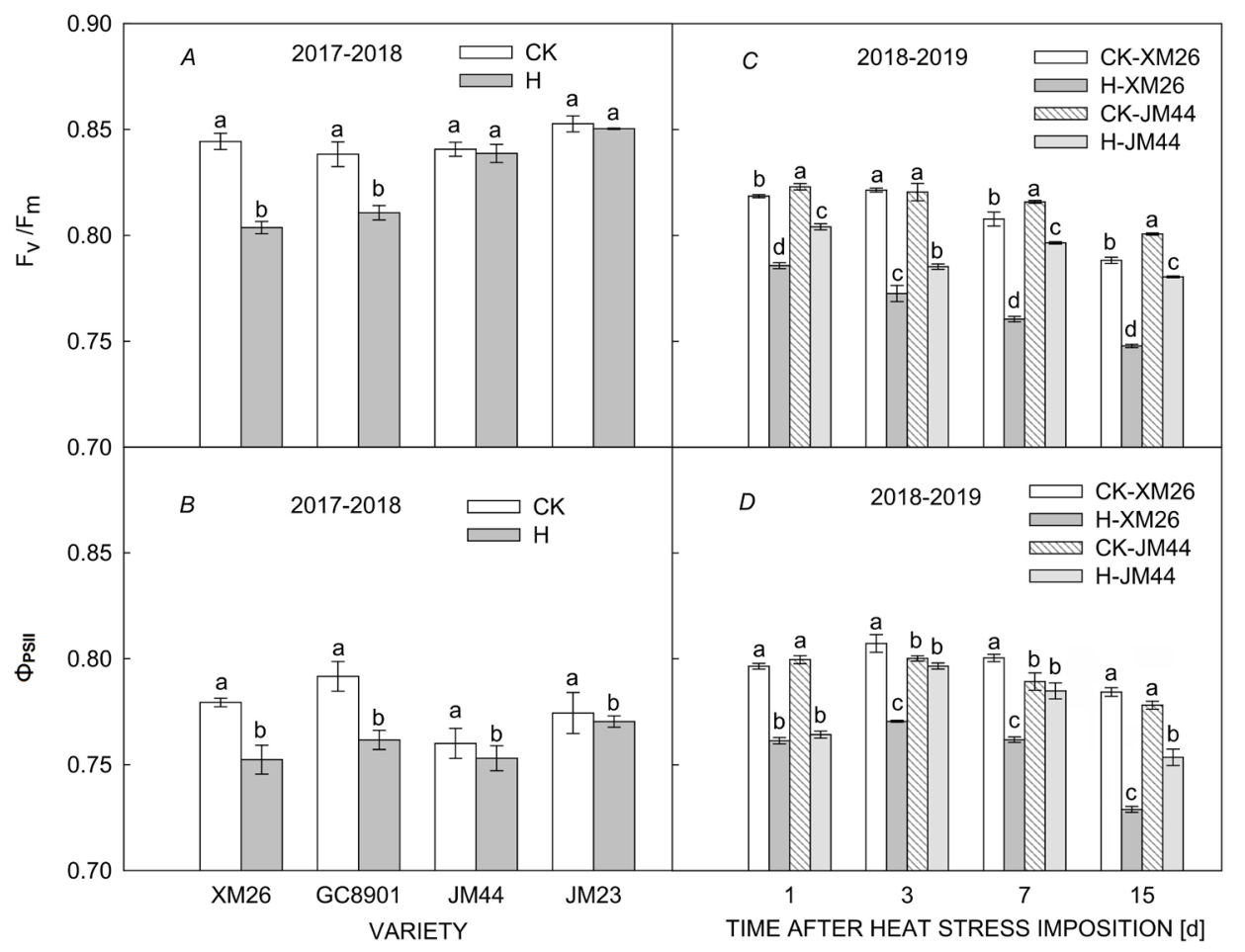

Fig. 5. Effect of heat stress on chlorophyll fluorescence parameters of flag leaves in different wheat varieties. CK - control treatment; $\mathrm{F}_{\mathrm{v}} / \mathrm{F}_{\mathrm{m}}$ - maximum quantum yield of PSII photochemistry; GC8901 - Gaocheng8901; H - heat stress treatment; JM44 - Jimai44; JM23 Jimai23; XM26 - Xinmai26; $\Phi_{\mathrm{PSII}}-$ effective quantum yield of PSII photochemistry. Values are means $\pm \mathrm{SD}, n=3$. Different lowercase letters indicate significant differences at $P<0.05$.

Table 2. Grain-filling characteristics of different wheat varieties under heat stress and control conditions.

\begin{tabular}{lllllll}
\hline Season & Variety & Treatment & $\begin{array}{l}\text { Time of maximum } \\
\text { filling rate [d] }\end{array}$ & $\begin{array}{l}\text { Maximum grain- } \\
\text { filling rate } \\
{\left[\mathrm{mg} \mathrm{grain}^{-1} \mathrm{~d}^{-1}\right]}\end{array}$ & $\begin{array}{l}\text { Duration of } \\
\text { maximum grain } \\
\text { filling [d] }\end{array}$ & $R^{2}$ \\
\hline 2017-2018 & XM26 & Control & 15.73 & 1.72 & 12.36 & 0.9967 \\
& & Heat & 15.03 & 1.55 & 12.60 & 0.9940 \\
& GC8901 & Control & 14.64 & 1.68 & 12.21 & 0.9921 \\
& & Heat & 13.92 & 1.47 & 12.78 & 0.9935 \\
& \multirow{2}{*}{ JM44 } & Control & 13.31 & 1.69 & 13.71 & 0.9820 \\
& & Heat & 11.71 & 1.49 & 15.77 & 0.9836 \\
& JM23 & Control & 13.67 & 1.94 & 13.15 & 0.9788 \\
& & Heat & 12.08 & 1.78 & 14.05 & 0.9780 \\
& XM26 & Control & 14.41 & 1.50 & 12.38 & 0.9947 \\
& & Heat & 12.89 & 1.18 & 13.23 & 0.9934 \\
& GC8901 & Control & 13.87 & 1.48 & 14.03 & 0.9911 \\
& & Heat & 12.60 & 1.28 & 13.06 & 0.9869 \\
& \multirow{2}{*}{ JM44 } & Control & 16.07 & 2.01 & 11.88 & 0.9867 \\
& \multirow{2}{*}{ JM23 } & Heat & 15.15 & 1.48 & 13.37 & 0.9903 \\
& Control & 15.96 & 2.00 & 12.17 & 0.9879 \\
& Heat & 12.60 & 1.53 & 14.28 & 0.9880 \\
\hline
\end{tabular}


GC8901 in both seasons and the leaf mass of XM26 and JM44 significantly increased in 2017-2018 and 20182019, respectively.

Correlation analysis: Grain yield (GY) was significantly related to the effective quantum yield of PSII photochemistry $\left(\Phi_{\text {PSII }}\right)$, dry mass $(\mathrm{DM})$, thousand kernel mass $(\mathrm{TKM})$, and net photosynthetic rate $\left(P_{\mathrm{N}}\right)$ under control (Fig. 4S, supplement). Under heat stress, grain yield was significantly related to thousand kernel mass (TKM), grain number per panicle $(\mathrm{GN})$, and transpiration rate $(E)$ (Fig. 4S). The correlation coefficient of grain yield (GY) with dry mass $(\mathrm{DM})$ at maturity stage, and net photosynthetic rate $\left(P_{\mathrm{N}}\right)$ decreased under heat stress as compared to control.

\section{Discussion}

This experiment studies the effects of long-term heat stress by imposing a high temperature $\left(9-12^{\circ} \mathrm{C}\right.$ higher than the control) for $7 \mathrm{~d}$ starting at $10 \mathrm{~d}$ after the anthesis stage of four wheat varieties with different heat tolerance in 2017-2018 and 2018-2019 seasons. Changes in photosynthesis parameters under high-temperature stress are good indicators of plant heat resistance (Wahid et al. 2007). Chl fluorescence is used to assess the effects of environmental changes on photosynthesis indirectly. It has been reported that PSII has high thermal sensitivity (Dash and Mohanty 2001, Sharkey 2005, Correia et al. 2021), but high temperatures below $40^{\circ} \mathrm{C}$ do not seriously affect PSII activity (Allakhverdiev et al. 2008). The ratio of variable fluorescence to maximum fluorescence $\left(\mathrm{F}_{\mathrm{v}} / \mathrm{F}_{\mathrm{m}}\right)$ determines the maximum quantum efficiency of PSII, while low $\mathrm{F}_{\mathrm{v}} / \mathrm{F}_{\mathrm{m}}$ under stress indicates damage to the PSII reaction center. In the present study, $F_{\mathrm{v}} / \mathrm{F}_{\mathrm{m}}$ of four varieties was measured after $5 \mathrm{~d}$ of heat stress in 2017-2018, and JM44 and XM26 were measured after $1,3,7$, and $15 \mathrm{~d}$ of heat stress in 2018-2019. The $F_{\mathrm{v}} / \mathrm{F}_{\mathrm{m}}$ decreased significantly in heat-sensitive varieties (GC8901 and XM26), while heat-resistant varieties (JM44 and JM23) did not show any significant reduction in 2017-2018, indicating that the heat-resistant varieties still had a high photon energy conversion efficiency under thermal stress. The low $\mathrm{F}_{\mathrm{v}} / \mathrm{F}_{\mathrm{m}}$ values indicated damage to the thylakoid membranes (Kadir et al. 2007). The less damage to the PSII may be related to higher antioxidant activity in heat-resistant varieties. The $\mathrm{F}_{\mathrm{v}} / \mathrm{F}_{\mathrm{m}}$ and $\Phi_{\mathrm{PSII}}$ of XM26 and JM44 showed a downward trend after thermal stress, especially the heat-sensitive species XM26 in 20182019. Thus, it is shown that the heat-resistant varieties have a high PSII regulation ability to heat stress and can maintain a higher activity of PSII. Previous studies have also shown that the $\mathrm{F}_{\mathrm{v}} / \mathrm{F}_{\mathrm{m}}$ and $\Phi_{\text {PSII }}$ of wheat are associated with heat resistance and are significantly reduced under thermal stress (Dash and Mohanty 2001). Furthermore, the heat-resistant variety (JM44) showed less damage to PSII after heat stress than the heat-sensitive XM26.

The rate of flag leaf photosynthesis of all four varieties decreased after thermal stress in a range between 23.8 and $39.5 \%$. The previous studies also showed that temperatures above $40^{\circ} \mathrm{C}$ might cause damage to the photosynthetic apparatus (Liu et al. 2017, Balla et al. 2019), which in the present study reached $>40^{\circ} \mathrm{C}$ at midday. The decline in photosynthesis depends on the variety and the time and duration of heat stress (Feng et al. 2014, Balla et al. 2019). The rate of photosynthesis increased after $3 \mathrm{~d}$ of heat stress and gradually decreased with the increase of stress time indicating that the damage to photosynthetic apparatus or

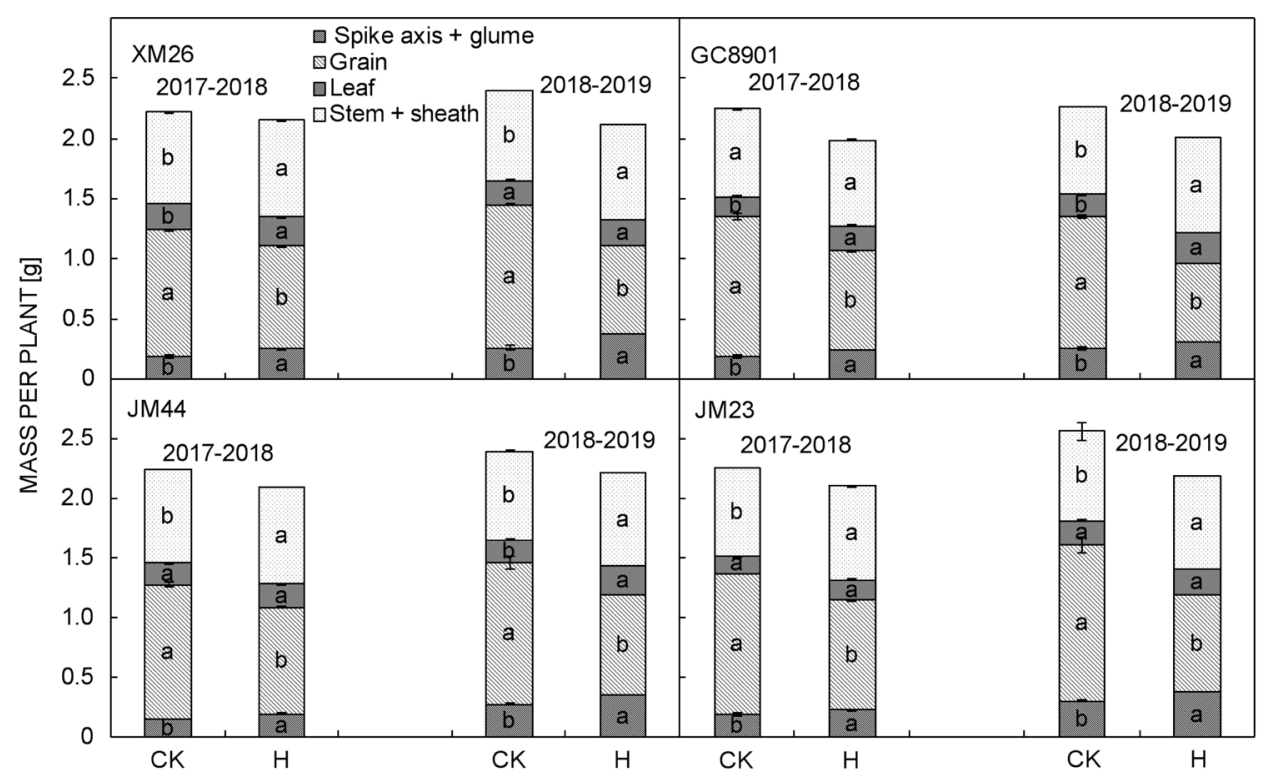

Fig. 6. Dry matter accumulation and partitioning of aboveground plants at maturity in two seasons of four wheat varieties. CK - control treatment; GC8901 - Gaocheng8901; H - heat stress treatment; JM44 - Jimai44; JM23 - Jimai23; XM26 - Xinmai26. Values are means $\pm \mathrm{SD}, n=3$. Different lowercase letters indicate significant differences at $P<0.05$. 
enzymes increased with the extension of thermal stress time. Thus, the photosynthesis system had a specific regulatory capacity for thermal stress.

Previous studies have shown that the photosynthesis of plants recovers fast after the release of thermal stress of $38^{\circ} \mathrm{C}$ (Correia et al. 2021). Our research shows that after removing $10 \mathrm{~d}$ of thermal stress, the photosynthesis of plants did not recover but showed a further reduction, especially in heat-sensitive variety. This indicates irreversible damage to the structure of the chloroplast thylakoid membrane and photosynthesis-related proteins when the maximum temperature of thermal stress exceeds $38^{\circ} \mathrm{C}$ (Feng et al. 2014). Further research is needed to study the effects of relatively long-term thermal stress on the structure of the thylakoid membrane and its associated proteins.

In this study, the transpiration rate increased significantly at all stages of thermal stress, indicating that the stomatal pores did not exhibit significant closure to limit the transpiration rate. This also shows that the decrease in photosynthesis was not caused by thermally induced closure of stomata (Feng et al. 2014). Furthermore, transpiration efficiency significantly decreased even when the heat stress was removed. However, the heat-resistant variety (JM44) showed higher recovery after heat stress by maintaining higher transpiration efficiency at 1,3 , and $15 \mathrm{~d}$ of heat stress. Thus, maintaining high transpiration efficiency under heat stress would be an important characteristic of heat resistance.

It has been reported that thermal stress accelerates the grain-filling rate of seeds (Yin et al. 2009, Fischer 2011), while severe heat stress could reduce it (Elía et al. 2018). In the present study, we did not find the positive effect of heat stress on grain-filling rate showing that the relative long-term heat stress had decreased the grain-filling rates of four varieties and accelerated the grain-filling process. These results indicated that the effect of heat depends on the timing, temperature, and duration of heat stress (Rezaei et al. 2018, Balla et al. 2019). We also found that the magnitude of reduction in grain-filling rate varied between varieties. The heat-resistant varieties (JM44 and JM23) had higher grain-filling rates than that of the heat-sensitive varieties (XM26 and GC8901), which was consistent with that the heat tolerant cultivars could maintain a high grainfilling rate under heat stress (Dias and Lidon 2009). The grain-filling rate is a useful trait to improve tolerance to heat stress during the grain-filling stage. The maximum grain-filling rate decreased in all varieties under heat stress over control, whereas the duration of maximum grain-filling rates increased in all varieties, especially in heat-resistant varieties (JM44 and JM23). This can be a self-regulation pathway response to long-term heat stress to compensate for the reduction in the duration of grain filling.

Plant tolerance to thermal stress is associated with increased antioxidant capacity (Goyal et al. 2010, Zhang et al. 2016). Previous studies have shown that the production of hydrogen peroxide and activities of peroxidase and superoxide dismutase are related to thermal stress tolerance during grain filling and the ability to obtain heat resistance (Zhao et al. 2007, Almeselmani et al. 2006, 2009). This study shows that the flag leaves of JM44 and JM23 maintained high activity of superoxide dismutase and catalase under thermal stress to remove and decompose excess reactive oxygen and hydrogen peroxide caused by thermal stress and maintain high photosynthesis ability. Furthermore, the MDA content in JM44 and JM23 flag leaves was lesser than that of GC8901 and XM26 which indicated that JM44 and JM23 suffer from minor damage to the structure and function of cell membranes under thermal stress, which is one of the reasons for JM44 and JM23 having high photosynthesis and heat resistance.

Heat stress can inhibit Chl biosynthesis and cause a decline in Chl content due to heat-induced damage to thylakoids (Ristic et al. 2007). Our study found that heat stress significantly affected the Chl contents of four varieties, and chlorophyll was severely damaged even after the end of heat stress. This indicated that heat stress irreversibly damaged the Chl biosynthesis, particularly in heat-sensitive varieties.

Global warming has accelerated crop development and shortened the reproductive period of crops (Tao et al. 2012). It has been reported that increasing the temperature of the wheat canopy by $1.5^{\circ} \mathrm{C}$ during the entire fertility period resulted in a $10-d$ reduction in the length of the whole reproductive period (Tian et al. 2012). Heat stress after flowering significantly reduces reproductive growth time (Bergkamp et al. 2018, Chen et al. 2018). In this study, thermal stress shortens the number of days from flowering to maturity and the varieties vary greatly in this parameter. Heat-resistant varieties (JM44 and JM23) show more extended reproductive periods than that of heatsensitive varieties (XM26 and GC8901) under long-term thermal stress. The long seed-filling time of heat-resistant varieties may be related to the high antioxidant ability and photosynthesis output capacity under thermal stress, which is the basis for heat-resistant varieties to obtain higher grain mass.

The heat resistance is related to the genotype with stable photosynthesis and the high storage capacity. Grain yield reduction under heat stress is mainly associated with reduced photosynthesis and stem reserve (Blum 1998, Yang et al. 2002). The study found that dry matter accumulation decreased during the whole ripening period under long-term thermal stress, which also reduced grain quality. This indicated that the transport of nutrients and reserves from vegetative organs to seeds is significantly reduced (Farooq et al. 2011). The contribution of stem reserve to seed filling is genotype-dependent (Yang et al. 2002). The results showed that the seed assimilation rate of heat-sensitive varieties (XM26 and GC8901) is lesser than that of heat-resistant varieties (JM44 and JM23), which indicates that heat-resistant varieties have a higher ability to convert assimilation material stored in nutritional organs into grains. Temperatures above $30^{\circ} \mathrm{C}$ are reported to reduce significantly the assimilation of the flag leaves to the grain but the temperature does not affect the transport in the stems (Wardlaw and Moncur 1995). This study found that the effect of thermal stress on the assimilation of nutritional organs was in the order of spike axis and 
glume $>$ leaves $>$ stem and sheath, indicating that thermal stress had a more significant effect on the distribution of assimilation in spike axis and glume than in stem. Therefore, it may be an essential way to improve grain yield and heat resistance by increasing the transport of spike axis and glume to grain.

Our study showed that thermal stress had significant adverse effects on seed yield and yield-related factors (Table 1). The average interannual and intervarietal reduction in grain yield by long-term heat stress was $23 \%$. The average yield reduction in the present study was relatively higher than the reduction $(8.9 \%)$ under short-term thermal stress for $3 \mathrm{~d}$ (Feng et al. 2014) and lower than the reduction $(57.3 \%)$ under long-term postflower thermal stress for $14 \mathrm{~d}$ (Schittenhelm et al. 2020). The maximum temperature in the above studies was $47.2^{\circ} \mathrm{C}$ while the maximum temperature attained in the present study was $48.8^{\circ} \mathrm{C}$, i.e., a $1.6^{\circ} \mathrm{C}$ difference from the previous. The reduction in yield by heat stress varies with the temperature and the length of heat stress duration. Furthermore, the duration of thermal stress is one of the critical factors in determining the reduction of grain yield and could explain $51.6 \%$ of plant phenotype variation (Balla et al. 2019).

The mass of thousand grains under high-temperature stress is associated with grain yield (Mondal et al. 2020) and is used as a heat-resistance indicator for wheat varieties (Feng et al. 2014, Cao et al. 2015). The experimental study shows that the decrease in the yield of winter wheat varieties under the long-term thermal stress is mainly related to the reduction in the number of spike grains and the reduction of thousand kernel mass because the grain number is determined by grain growth rate and duration of the grain-filling period (Zhang et al. 2019). The average decrease of grain mass between years and varieties is $15.6 \%$. After thermal stress, the decrease of thousand kernel mass is higher than the decrease of the number of spike grains, which indicates that the main reason for reducing grain yield by thermal stress is the reduction in grain-filling rate and time (Feng et al. 2014). There were significant differences in the response of different varieties to long-term thermal stress and the yield of JM23 and JM44 decreased comparatively less, mainly because they maintained a higher number of spikes and thousand kernel mass than that of XM26 and GC8901 after thermal stress.

In conclusion, long-term heat stress decreased the maximum quantum yield of PSII photochemistry $\left(\mathrm{F}_{\mathrm{v}} / \mathrm{F}_{\mathrm{m}}\right)$, the effective quantum yield of PSII photochemistry $\left(\Phi_{\text {PSII }}\right)$, and the net photosynthetic rate, which resulted in low photosynthetic performance and grain-filling rates. It also increased the antioxidant ability and MDA content, resulting in low chlorophyll content and a short filling period (Fig. 5S, supplement). The lower filling rates and short filling period under heat stress caused lesser assimilation transport to grain, resulting in reduced grain mass, spike number, and grain yield. Thus, heat-sensitive varieties (XM26 and GC8901) exhibited more damage to the parameters mentioned above under heat stress than heat-resistant varieties (JM44 and JM23), so they showed higher yield reduction.

\section{References}

Allakhverdiev S.I., Kreslavski V.D., Klimov V.V. et al.: Heat stress: an overview of molecular responses in photosynthesis. Photosynth. Res. 98: 541-550, 2008.

Almeselmani M., Deshmukh P.S., Sairam R.K. et al.: Protective role of antioxidant enzymes under high temperature stress. Plant Sci. 171: 382-388, 2006.

Almeselmani M., Deshmukh P.S., Sairam R.K.: High temperature stress tolerance in wheat genotypes: Role of antioxidant defence enzymes. - Acta Agron. Hung. 57: 1-14, 2009.

Álvaro F., Isidro J., Villegas D. et al.: Breeding effect on grain filling, biomass partitioning, and remobilization in Mediterranean durum wheat. - Agron J. 100: 361-370, 2008.

Balla K., Karsai I., Bónis P. et al.: Heat stress responses in a large set of winter wheat cultivars (Triticum aestivum L.) depend on the timing and duration of stress. - PLoS ONE 14: e0222639, 2019.

Bergkamp B., Impa S.M., Asebedo A.R. et al.: Prominent winter wheat varieties response to post-flowering heat stress under controlled chambers and field based heat tents. - Field Crop. Res. 222: 143-152, 2018.

Blum A.: Improving wheat grain filling under stress by stem reserve mobilisation. - Euphytica 100: 77-83, 1998.

Camejo D., Rodríguez P., Morales M.A. et al.: High temperature effects on photosynthetic activity of two tomato cultivars with different heat susceptibility. - J. Plant Physiol. 162: 281-289, 2005.

Cao X., Mondal S., Cheng D. et al.: Evaluation of agronomic and physiological traits associated with high temperature stress tolerance in the winter wheat cultivars. - Acta Physiol. Plant. 90: 89-90, 2015 .

Chen Y., Zhang Z., Tao F.L. et al.: Impacts of heat stress on leaf area index and growth duration of winter wheat in the North China Plain. - Field Crop. Res. 222: 230-237, 2018.

Correia P.M.P., da Silva A.B., Roitsch T. et al.: Photoprotection and optimization of sucrose usage contribute to faster recovery of photosynthesis after water deficit at high temperatures in wheat. - Physiol. Plantarum 172: 615-628, 2021.

Dash S., Mohanty N.: Evaluation of assays for the analysis of thermo-tolerance and recovery potentials of seedlings of wheat (Triticum aestivum L.) cultivars. - J. Plant Physiol. 158: 1153-1165, 2001.

Dhindsa R.S., Plumb-Dhindsa P., Thorpe T.A.: Leaf senescence: correlated with increased levels of membrane permeability and lipid peroxidation, and decreased levels of superoxide dismutase and catalase. - J. Exp. Bot. 32: 93-101, 1981.

Dias A.S., Lidon F.C.: Evaluation of grain filling rate and duration in bread and durum wheat, under heat stress after anthesis. J. Agron. Crop Sci. 195: 137-147, 2009.

Elía M., Slafer G.A., Savin R.: Yield and grain weight responses to post anthesis increases in maximum temperature under field grown wheat as modified by nitrogen supply. - Field Crop. Res. 221: 228-237, 2018.

Fahad S., Hussain S., Saud S. et al.: A combined application of biochar and phosphorus alleviates heat-induced adversities on physiological, agronomical and quality attributes of rice. - Plant Physiol. Bioch. 103: 191-198, 2016.

Farooq M., Bramley H., Palta J.A., Siddique K.H.M.: Heat stress in wheat during reproductive and grain filling phases. - Crit. Rev. Plant Sci. 30: 491-507, 2011.

Feng B., Liu P., Li G. et al.: Effect of heat stress on the photosynthetic characteristics in flag leaves at the grain-filling stage of different heat-resistant winter wheat varieties. J. Agron. Crop Sci. 200: 143-155, 2014. 
Fischer R.A.: Wheat physiology: a review of recent developments. - Crop Pasture Sci. 62: 95-114, 2011.

Goyal M., Asthir B.: Polyamine catabolism influences antioxidative defense mechanism in shoots and roots of five wheat genotypes under high temperature stress. - Plant Growth Regul. 60: 13-25, 2010.

IPCC 2018: Summary for Policymakers.-In: Masson-DelmotteV., Zhai P., Pörtner H.-O. et al. (ed.): Global Warming of $1.5^{\circ} \mathrm{C}$. An IPCC Special Report on the impacts of global warming of $1.5^{\circ} \mathrm{C}$ above pre-industrial levels and related global greenhouse gas emission pathways, in the context of strengthening the global response to the threat of climate change, sustainable development, and efforts to eradicate poverty. Pp. 32. World Meteorological Organization, Geneva 2018.

Kadir S., von Weihe M., Al-Khatib K.: Photochemical efficiency and recovery of photosystem II in grapes after exposure to sudden and gradual heat stress. - J. Am. Soc. Hortic. Sci. 132: 764-769, 2007.

Li S.Q., Shao M.A., Li Z.Y. et al.: [Review of characteristics of wheat grain fill and factors to influence it.] - Acta Bot. Bor.-Occident. Sin. 23: 2031-2039, 2003. [In Chinese]

Liu B., Asseng S., Wang A. et al.: Modelling the effects of postheading heat stress on biomass growth of winter wheat. - Agr. Forest Meteorol. 247: 476-490, 2017.

Mondal S., Dutta S., Crespo-Herrera L. et al.: Fifty years of semi-dwarf spring wheat breeding at CIMMYT: Grain yield progress in optimum, drought and heat stress environments. Field Crop. Res. 250: 107757, 2020.

Rezaei E.E., Siebert S., Manderscheid R. et al.: Quantifying the response of wheat yields to heat stress: The role of the experimental setup. - Field Crop. Res. 217: 93-103, 2018.

Ristic Z., Bukovnik U., Prasad P.V.V.: Correlation between heat stability of thylakoid membranes and loss of chlorophyll in winter wheat under heat stress. - Crop Sci. 47: 2067-2073, 2007.

Sanghera A.K., Thind S.K.: Dry matter accumulation and partitioning in wheat genotypes as affected by sowing date mediated heat stress. - Int. J. Sci. Res. 3: 3-6, 2014.

Schittenhelm S., Langkamp-Wedde T., Kraft M. et al.: Effect of two-week heat stress during grain filling on stem reserves, senescence, and grain yield of European winter wheat cultivars. - J. Agron. Crop Sci. 206: 722-733, 2020.

Sharkey T.D.: Effects of moderate heat stress on photosynthesis: importance of thylakoid reactions, rubisco deactivation, reactive oxygen species, and thermo tolerance provided by isoprene. - Plant Cell Environ. 28: 269-277, 2005.

Shirdelmoghanloo H., Cozzolino D., Lohraseb I., Collins N.C. Truncation of grain filling in wheat (Triticum aestivum) triggered by brief heat stress during early grain filling: association with senescence responses and reductions in stem reserves. - Funct. Plant Biol. 43: 919-930, 2016.

Streck N.A.: Climate change and agroecosystems: the effect of elevated atmospheric $\mathrm{CO}_{2}$ and temperature on crop growth, development and yield. - Ciênc. Rural 35: 730-740, 2005.

Tack J., Barkley A., Nalley L.L.: Effect of warming temperatures on US wheat yields. - P. Natl. Acad. Sci. USA 112: 69316936, 2015.
Tahir I.S.A., Nakata N.: Remobilization of nitrogen and carbohydrate from stems of bread wheat in response to heat stress during grain filling. - J. Agron. Crop Sci. 191: 106-115, 2005.

Talukder A.S.M.H.M., McDonald G.K., Gill G.S.: Effect of short-term heat stress prior to flowering and early grain set on the grain yield of wheat. - Field Crop. Res. 160: 54-63, 2014.

Tao F., Zhang Z., Zhang S. et al.: Response of crop yields to climate trends since 1980 in China. - Clim. Res. 54: 233-247, 2012.

Tian Y., Chen J., Chen C. et al:: Warming impacts on winter wheat phenophase and grain yield under field conditions in Yangtze Delta Plain, China. - Field Crop. Res. 134: 193-199, 2012.

Urban O., Hlaváčová M., Klem K. et al.: Combined effects of drought and high temperature on photosynthetic characteristics in four winter wheat genotypes. - Field Crop. Res. 223: 137$149,2018$.

Viswanathan C., Khanna-Chopra R.: Effect of heat stress on grain growth, starch synthesis and protein synthesis in grains of wheat (Triticum aestivum L.) varieties differing in grain weight stability. - J. Agron. Crop Sci. 186: 1-7, 2001.

Wahid A., Gelani S., Ashraf M., Foolad M.R.: Heat tolerance in plants: an overview. - Environ. Exp. Bot. 61: 199-223, 2007.

Wang J., Wang E., Yang X. et al.: Increased yield potential of wheat-maize cropping system in the North China Plain by climate change adaptation. - Climatic Change 113: 825-840, 2012.

Wang X., Cai J., Jiang D. et al.: Pre-anthesis high-temperature acclimation alleviates damage to the flag leaf caused by postanthesis heat stress in wheat. - J. Plant Physiol. 168: 585-593, 2011.

Wardlaw I.F., Moncur L.: The response of wheat to high temperature following anthesis. I. The rate and duration of kernel filling. - Aust. J. Plant Physiol. 22: 391-397, 1995.

Yang J., Sears R.G., Gill B.S., Paulsen G.M.: Genotypic differences in utilization of assimilate sources during maturation of wheat under chronic heat and heat shock stresses. - Euphytica 125: 179-188, 2002.

Ye L., Xiong W., Li Z et al.: Climate change impact on China food security in 2050. - Agron. Sustain. Dev. 33: 363-374, 2013.

Yin X., Guo W., Spiertz J.H.: A quantitative approach to characterize sink-source relationships during grain filling in contrasting wheat genotypes. - Field Crop. Res. 114: 119-126, 2009.

Zhang C.X., Fu G.F., Yang X.Q. et al.: Heat stress effects are stronger on spikelets than on flag leaves in rice due to differences in dissipation capacity. - J. Agron. Crop Sci. 202: 394-408, 2016.

Zhang H., Richards R., Riffkin P. et al.: Wheat grain number and yield: The relative importance of physiological traits and source-sink balance in southern Australia. - Eur. J. Agron. 110: 125935, 2019.

Zhao H., Dai T.B., Jing Q. et al.: Leaf senescence and grain filling affected by post-anthesis high temperatures in two different wheat cultivars. - Plant Growth Regul. 51: 149-158, 2007.

(C) The authors. This is an open access article distributed under the terms of the Creative Commons BY-NC-ND Licence. 